\title{
Update on bariatric surgical procedures and an introduction to the implantable weight loss device: the Maestro Rechargeable System
}

This article was published in the following Dove Press journal:

Medical Devices: Evidence and Research

17 August 2016

Number of times this article has been viewed

\author{
Stephanie S Hwang' \\ Mark C Takata' \\ Ken Fujioka ${ }^{2}$ \\ William Fuller' \\ 'Division of General/Bariatric \\ Surgery, Scripps Clinic Weight \\ Management, ${ }^{2}$ Division of Diabetes \\ and Endocrinology, Scripps Clinic, La \\ Jolla, CA, USA
}

Correspondence: William Fuller Division of General/Bariatric Surgery, Scripps Clinic Weight Management, I0666 N Torrey Pines Road, La Jolla, CA 92037, USA

Tel +l 8585548984

Fax +l 8585545055

Email fuller.william@scrippshealth.org

\begin{abstract}
There are many different methods of treating obesity, ranging from various medical options to several surgical therapies. This paper briefly summarizes current surgical options for weight loss with a focus on one of the newest US Food and Drug Administration-approved devices for surgical weight loss therapy, the Maestro Rechargeable System. Also known as the vagal blocking for obesity control implantable device, this tool blocks vagal nerve activity to induce weight loss.
\end{abstract}

Keywords: VBLOC device, vagal, vagus, obesity

\section{Introduction}

Obesity is a significant health risk in the US. More than one-third of the US population is affected according to the Centers for Disease Control and Prevention. ${ }^{1-4}$ Numerous studies of class II (body mass index [BMI] $>35 \mathrm{~kg} / \mathrm{m}^{2},<40 \mathrm{~kg} / \mathrm{m}^{2}$ ) and class III $\left(\mathrm{BMI} \geq 40 \mathrm{~kg} / \mathrm{m}^{2}\right)$ obese patients demonstrate that nonsurgical options for weight loss, though impactful, result in less weight loss when compared to surgical management. Patients undergoing bariatric surgery have improved longevity when compared with their counterparts who have not undergone surgery. ${ }^{5-9}$ As a consequence, the number of bariatric surgical procedures performed in the US has continued to increase annually, from 158,000 procedures in 2011 to 193,000 procedures in $2014 .^{10}$

Current surgical options performed in large volume in the US include laparoscopic Roux-en-Y gastric bypass (LRYGB), laparoscopic vertical sleeve gastrectomy (LVSG), and laparoscopic adjustable gastric band (LAGB) placement. Laparoscopic duodenal switch (DS)/biliopancreatic diversion is much less frequently performed. Saline-filled intragastric balloons have also recently been developed to endoscopically treat obesity. Designed to occupy space in the stomach, intragastric balloons induce satiety and reduce food intake. This paper will focus mostly on the LRYGB, LVSG, and to a lesser extent LAGB techniques. Articles were chosen for this review from PubMed searches of papers written in English from 2005 to 2015, and the papers that best reflected surgical outcomes for each procedure were selected based on the authors' experiences. For certain aspects of historical data, papers were reviewed from 2004 back through 1969.

\section{Surgical procedures}

LRYGB has emerged as a durable bariatric surgical procedure since the mid-1990s, ${ }^{11}$ although its open counterpart had been performed for weight loss since the $1960 \mathrm{~s}^{12}$ 
The procedure of gastric bypass has been well documented and can be performed with some variability, but the current iterations of the procedure utilize a small gastric pouch with a volume of $\sim 30$ cc to restrict meal size and a Roux-en-Y jejunojejunostomy reconstruction distally for drainage of the remnant stomach and biliopancreatic limb. ${ }^{13}$ Approximately, $30-40 \mathrm{~cm}$ distal to the ligament of Treitz, the jejunum is divided. The distal cut end of the jejunum (the Roux limb) is anastomosed to the gastric pouch, and the proximal cut end of the jejunum (the biliopancreatic limb) is anastomosed 75-150 $\mathrm{cm}$ distal to the gastrojejunostomy (Figure 1). Variable alimentary (Roux) limb lengths of 75-150 cm are constructed to affect a more extensive "bypass" of proximal intestines with varying results on weight loss. ${ }^{14,15}$

LVSG was initially introduced as part of the DS procedure in 1999. ${ }^{16}$ Since then, LVSG has emerged as an effective standalone surgery in which a narrow gastric conduit is created by stapling the stomach in a longitudinal fashion. ${ }^{17,18}$ The remaining stomach is excised, which is $\sim 70 \%$ of the

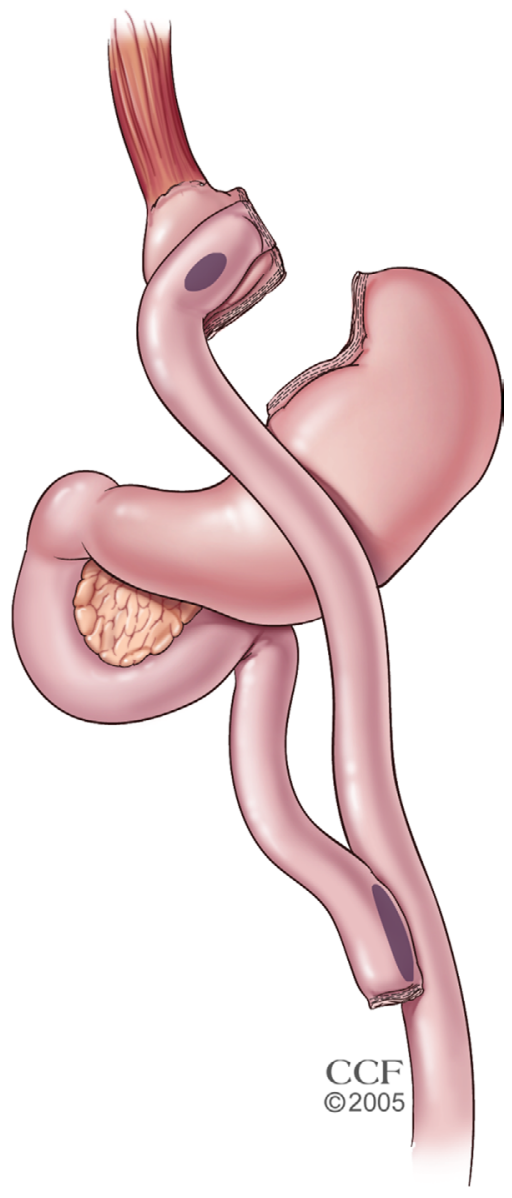

Figure I Roux-en-Y gastric bypass.

Note: Reprinted with permission, Cleveland Clinic Center for Medical Art \& Photography @ 2016. ${ }^{46}$ All Rights Reserved. gastric volume (Figure 2). The narrowness of the newly created "sleeve" stomach imparts portion control along with a reduction in appetite which may also be hormonally induced. Percent excess weight loss (\%EWL) is comparable to the Roux-en-Y gastric bypass (Table 1). LVSG is now recognized as the most commonly performed bariatric procedure in the US, comprising $60 \%$ of all bariatric procedures. ${ }^{19}$ Additionally, there seems to be a trend in the country of increased numbers of sleeve gastrectomies being performed and fewer adjustable gastric bands being implanted..$^{20,21}$

When comparing LVSG and LRYGB weight loss results, the procedures are comparable. There is a tendency toward higher \%EWL for LRYGB (Table 1). Excess body weight loss ranges between $46 \%$ and $81 \%$ for patients who have received LVSG compared to 59\%-94\% for patients receiving LRYGB. ${ }^{20,22-24}$ The complication rates for both the procedures are low (Figure 3). Bleeding complications range between $0 \%$ and $3.6 \%$ in patients undergoing LVSG compared with $1.5 \%$ $5 \%$ in patients undergoing LRYGB..$^{20,23-28}$ Leak rates range

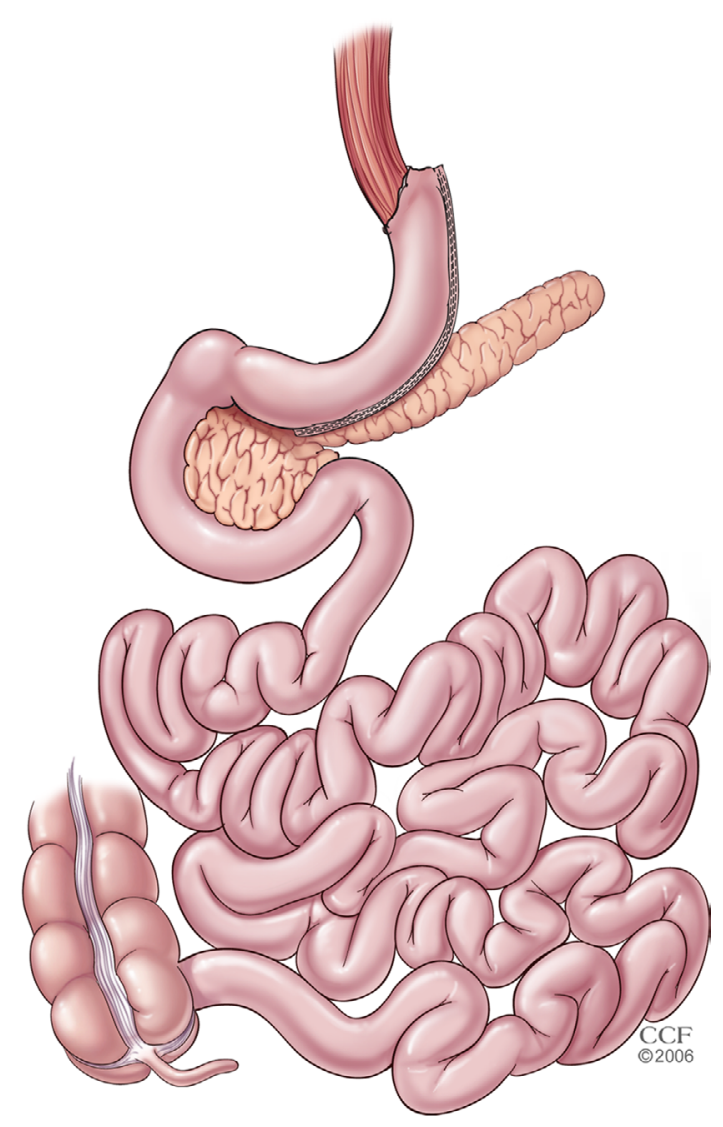

Figure 2 Sleeve gastrectomy.

Note: Reprinted with permission, Cleveland Clinic Center for Medical Art \& Photography @ 2016.46 All Rights Reserved. 
Table I Weight loss outcomes after LSG and comparator procedures

\begin{tabular}{|c|c|c|c|c|c|}
\hline References & Follow-up & Procedure & Preoperative BMI $\left(\mathrm{kg} / \mathrm{m}^{2}\right)$ & Postoperative BMI $\left(\mathrm{kg} / \mathrm{m}^{2}\right)$ & Weight loss at follow-up \\
\hline \multirow[t]{2}{*}{ Peterli et al, $2012^{53}$} & I year & LSG & $44.7 \pm 5.3$ & $32.0 \pm 5.5$ & $65.6 \pm 21.2 \% *$ \\
\hline & & LGB & $47.6 \pm 6.8$ & $31.1 \pm 7.5$ & $77.0 \pm 24.7 \% *$ \\
\hline \multirow[t]{2}{*}{ Lee et al, 20I I ${ }^{52}$} & I year & LSG & NR & $24.4 \pm 2.4$ & $76.3 \pm 38.9 \%$ \\
\hline & & LGB & & $22.8 \pm 2.2$ & $94.4 \pm 33.1 \%$ \\
\hline \multirow[t]{2}{*}{ Kehagias et al, 20I I ${ }^{49}$} & 3 year & LSG & $44.9 \pm 3.4$ & $29.6 \pm 4.1$ & $68.5 \%$ \\
\hline & & LGB & $45.8 \pm 3.7$ & $31.3 \pm 3.9$ & $62.1 \%$ \\
\hline \multirow[t]{2}{*}{ Lakdawala et al, $2011^{50}$} & 6 month & LSG & $43(34-59)$ & NR & $49 \pm 17.9 \%$ \\
\hline & & SILSG & $4 \mid(32-58)$ & & $51.7 \pm 19.9 \%$ \\
\hline \multirow[t]{2}{*}{ Schauer et al, $2012^{6}$} & I year & LSG & $36.1 \pm 3.9$ & $27.2 \pm 3.5$ & $81($ IQR 65-97)\%\# \\
\hline & & LGB & $37.0 \pm 3.3$ & $26.8 \pm 3.2$ & 88 (IQR 72-I0I)\%\# \\
\hline \multirow[t]{2}{*}{ Langer et al, $2005^{51}$} & 6 month & LSG & $48.3 \pm 5.7$ & NR & $61.4 \pm 16.3 \%$ \\
\hline & & SILSG & $46.7 \pm 3.5$ & & $28.7 \pm 10.6 \%$ \\
\hline \multirow[t]{2}{*}{ Himpens et al, $2006^{48}$} & 3 year & LSG & $39(30-53)^{\#}$ & $27.5(0-48)^{\#}$ & $66 \%(-3.1 \text { to }+152.4)^{\# \neq}$ \\
\hline & & LAGB & $37(30-47)^{\#}$ & I8 (0-39) & $48 \%(0-124.8)^{\# \ddagger}$ \\
\hline
\end{tabular}

Notes: Reprinted from Surg Obes Relat Dis, 9/5, Trastulli S, Desiderio J, Guarino S, et al, Laparoscopic sleeve gastrectomy compared with other bariatric surgical procedures: a systematic review of randomized trials, 8I6-830, Copyright $@(2013)$, with permission from Elsevier. ${ }^{24}$ Data were shown as the mean \pm standard deviation, if not otherwise specified; data on weight loss at the time of follow-up were presented as \%EWL, if not otherwise specified. Himpens et al reported the data on postoperative BMI in the form of median BMI decrease. *\%EBMIL, Percentage of excess body mass index loss; \#Median (range); ₹Percent of excess weight loss using the Metropolitan Tables.

Abbreviations: BMI, body mass index; \%EWL, percentage of excess weight loss; IQR, interquartile range; LAGB, laparoscopic adjustable gastric banding; LGB, laparoscopic gastric bypass; LSG, laparoscopic sleeve gastrectomy; NR, not reported; SILSG, single-incision laparoscopic sleeve gastrectomy.

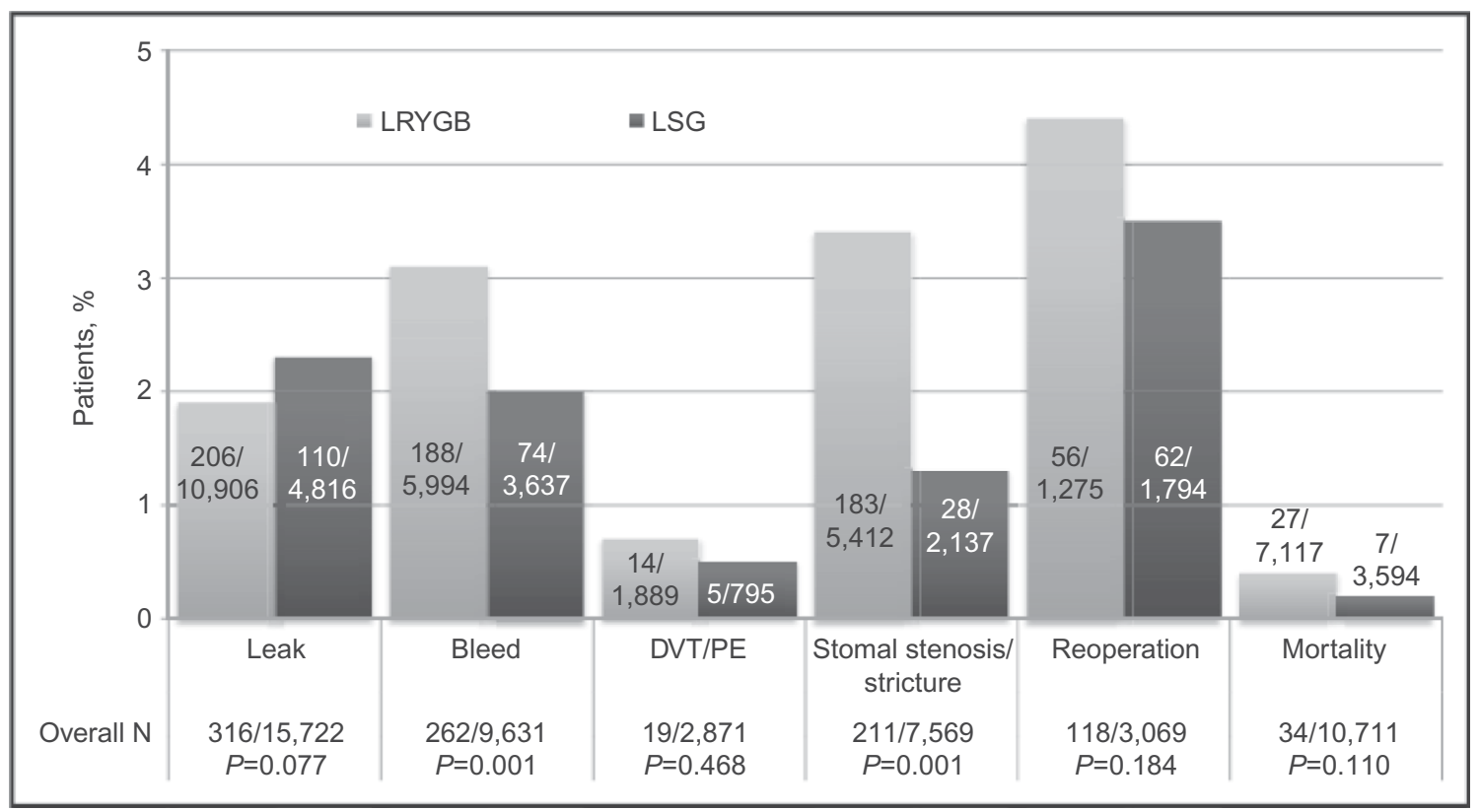

Figure 3 Thirty-day complication rates.

Notes: Reprinted from Am J Surg, 208/6, Zellmer J, Mathiason M, Kallies K, Kothari S, Is laparoscopic sleeve gastrectomy a lower risk bariatric procedure compared with laparoscopic Roux-en-Y gastric bypass? A meta-analysis, 903-910, Copyright (2014), with permission from Elsevier. ${ }^{27}$

Abbreviations: DVT, deep vein thrombosis; PE, pulmonary embolism; LRYGB, laparoscopic Roux-en-Y gastric bypass; LSG, laparoscopic sleeve gastrectomy.

between $0 \%$ and $2.3 \%$ in patients treated with LVSG compared with $0 \%-1.9 \%$ in patients treated with LRYGB. ${ }^{20,23-27}$ Venous thromboembolism complications including both deep venous thrombosis and pulmonary embolism rates range between $0.2 \%$ and $3.39 \%$ for patients who received LVSG compared to $0.2 \%-0.7 \%$ in patients who received LRYGB..$^{20,25-28}$ Obstruction, including stenosis or small bowel obstruction, occurred in $0 \%-1.3 \%$ of LVSG patients and $0 \%-3.4 \%$ of LRYGB patients. ${ }^{23-27}$ Mortality is rare for both operative procedures, ranging from $0 \%$ to $0.2 \%$ in patients who received an LVSG and $0 \%-0.4 \%$ in patients who received an LRYGB. ${ }^{20,24,27,28}$

The laparoscopic DS procedure is similar to a gastric bypass, except that the intestinal bypass portion of the procedure is more extensive - rather than a bypass limb of $75-150 \mathrm{~cm}$. Most of the small intestine is bypassed so that the common channel distal to the biliopancreatic to alimentary 


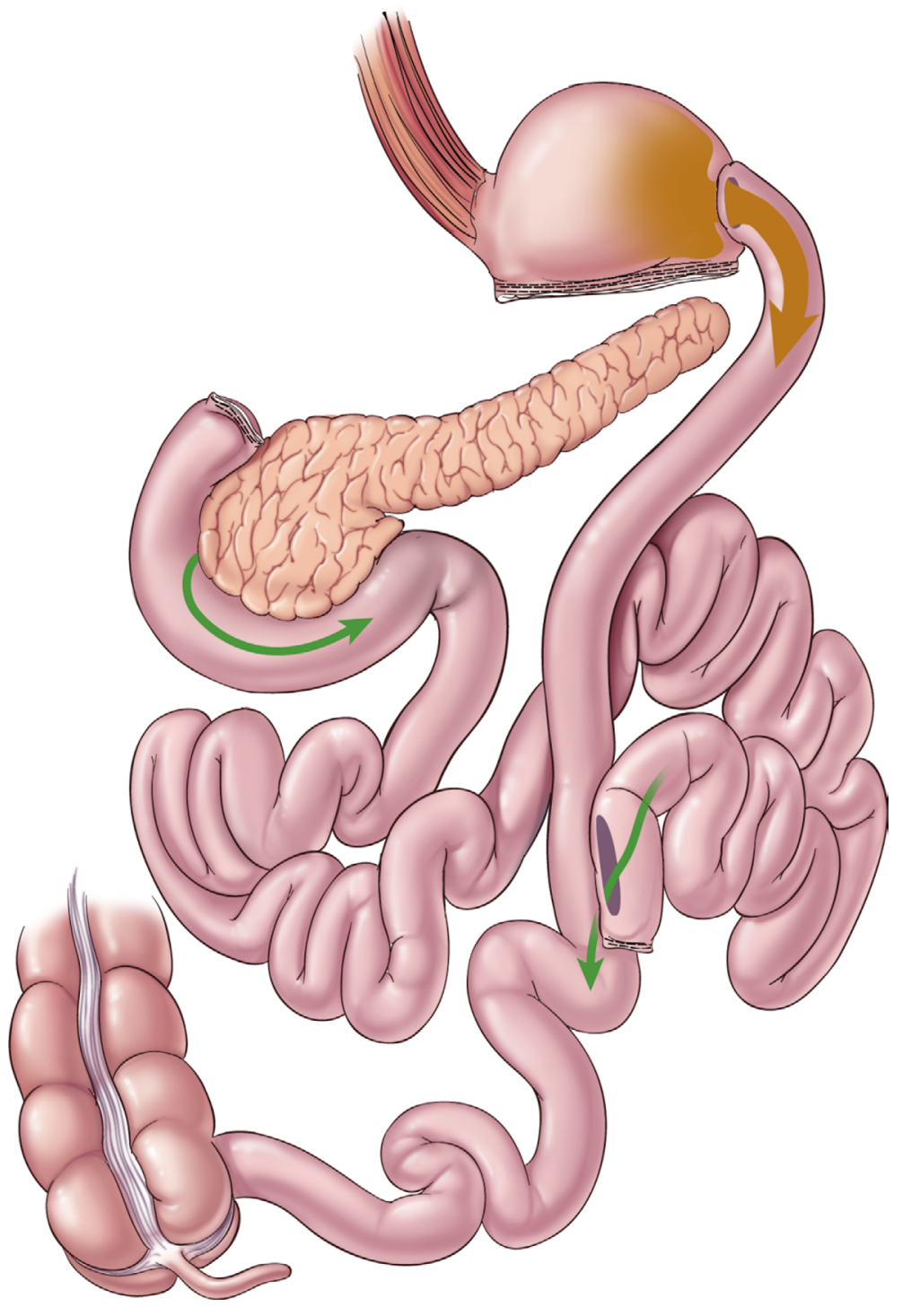

Figure 4 Duodenal switch (biliopancreatic diversion) procedure.

Notes: Reprinted with permission, Cleveland Clinic Center for Medical Art \& Photography @ $2016 .{ }^{46}$ All Rights Reserved. Green arrows illustrate flow of bile and pancreatic fluid through the new anatomy.

limb anastomosis is $50-100 \mathrm{~cm}$ long (Figure 4). Due to the steeper learning curve of the procedure and potentially higher risk of surgical complications and nutritional deficiencies, this procedure is performed less frequently than the LRYGB or LVSG techniques.

LAGBs have been established as a surgical method to help with weight loss since early 2000s in the US. As a percentage of surgical volume, LAGB has been performed with decreased frequency. In the procedure, a silastic-based band with a balloon along its circumference is placed on the stomach close to the gastroesophageal junction with the idea of forming a new, smaller gastric pouch to restrict meal size (Figure 5). However, surgeons in the US have moved away from gastric band placement due to widespread patient intolerance, less effective or slower weight loss, and a high rate of complications over long term..$^{29}$ Recent large cohort studies with long-term follow-up have shown that initial good results with the gastric band are short lived: mean \%EWL at 5 years range between $49 \%$ and $66.1 \%$ but drop to $41 \%-51.6 \%$ and lower after $9-10$ years and $21 \%$ after 15 years. ${ }^{29,30}$ Of the gastric band patients, $67 \%-78.5 \%$ of patients underwent a reoperation, most commonly for weight regain, port malfunction, and band slippage or erosion. ${ }^{29,30}$ In these studies, after follow-up periods of 13-15 years, $72.7 \%-77 \%$ of all bands were permanently explanted. ${ }^{29,30}$

With the decline in popularity of the gastric band, LRYGB and LVSG have become the predominant operations for the treatment of obesity in the last 5 years. ${ }^{21}$ However, only $1 \%-3 \%$ of the patients who qualify for bariatric surgery choose to undergo these operations. Many factors contribute to the limited adoption of bariatric surgery. One such factor 

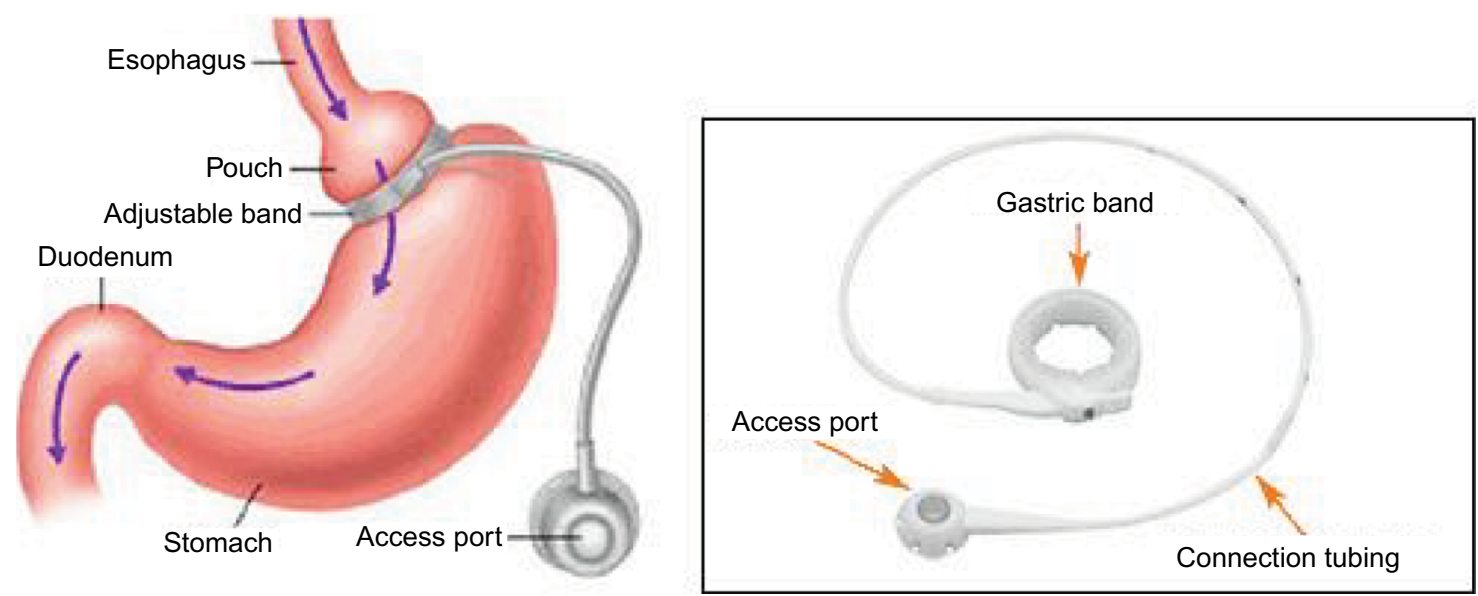

Figure 5 Adjustable gastric band.

Note: Reproduced from www.fda.gov [homepage on the Internet]. Maryland: Food and Drug Administration [updated August 5, 20I5]. Available from: http://www. fda.gov/ MedicalDevices/ProductsandMedicalProcedures/ObesityDevices/ucm350I34.htm. Accessed April 12, 2016. ${ }^{47}$
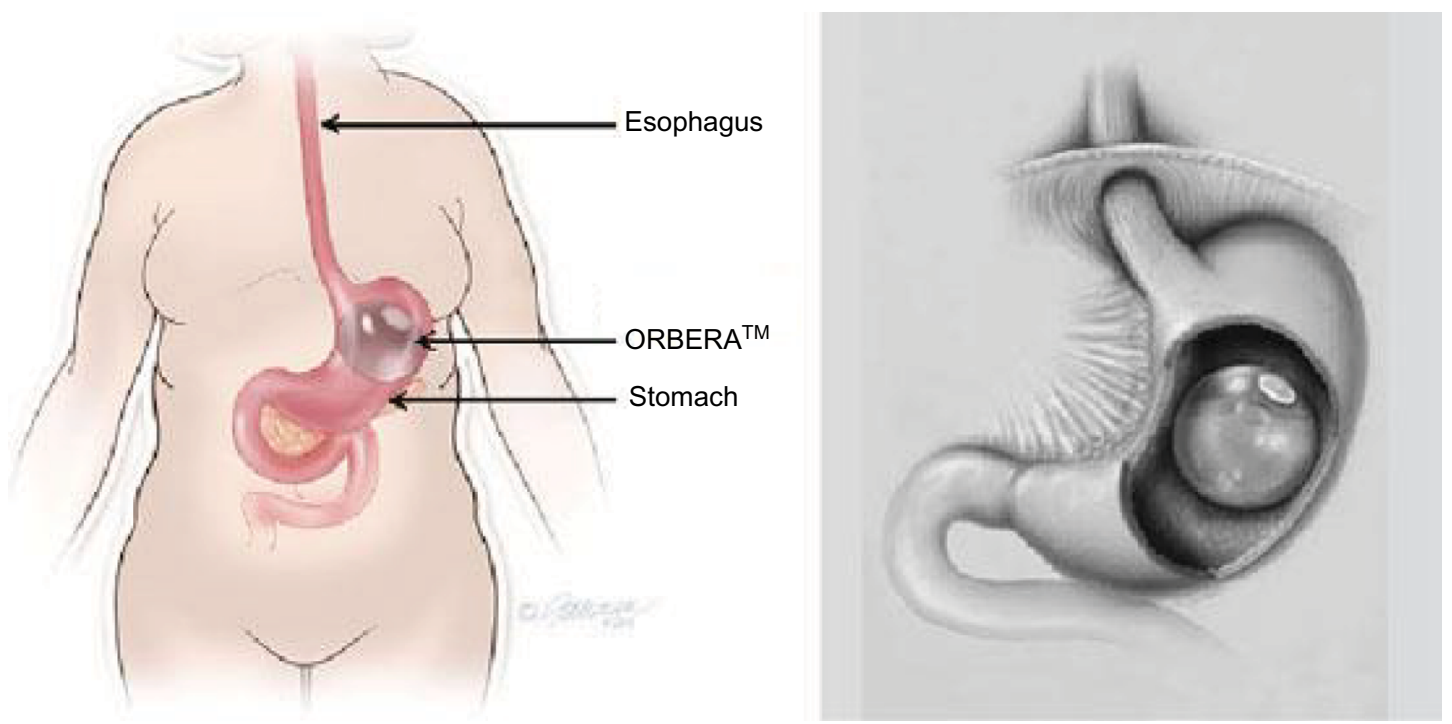

Figure 6 Intragastric balloon.

Notes: ORBERATM (Apollo Endosurgery, Inc., ORBERA Intragastric Balloon System, Austin, TX, USA). Reproduced from www.fda.gov [homepage on the Internet]. Maryland: Food and Drug Administration [updated August 5, 2015]. Available from: http://www.fda.gov/MedicalDevices/ProductsandMedicalProcedures/ObesityDevices/ucm350I34. htm. Accessed April 12, 2016. ${ }^{47}$

is the relatively small number of choices available to patients with severe obesity and the perceived invasive nature of these operations. As a result, there has been a significant increase in potential alternative options, including intragastric balloons and the Maestro Rechargeable System (vagal blocking for obesity control [VBLOC] device) (EnteroMedics Inc., St Paul, MN, USA).

\section{Intragastric balloons}

Intragastric balloons are a newly developed endoscopic therapy for weight loss. The balloons are endoscopically placed into the stomach and filled with saline, intending to occupy space in the stomach to induce satiety and decrease food intake (Figure 6). Studies have shown the balloons to induce $\%$ EWL of $25 \%-40 \% .{ }^{31}$ Side effects and complications include nausea, vomiting, abdominal pain, ulcer development, balloon deflation, and device migration. There are currently few long-term studies on the efficacy and safety of the intragastric balloons.

\section{The implantable weight loss device: the Maestro Rechargeable System}

The primary focus of this paper, the VBLOC device, utilizes the vagus nerve as the target of treatment. Instead of performing a permanent truncal vagotomy, the goal was to intermittently interrupt transmission of the vagus nerve, theoretically leading to less physiologic adaptation and therefore a more permanent effect. ${ }^{32}$ This has led to the development of the Maestro Rechargeable System (VBLOC device) which was approved by the US Food and Drug Administration (FDA) 


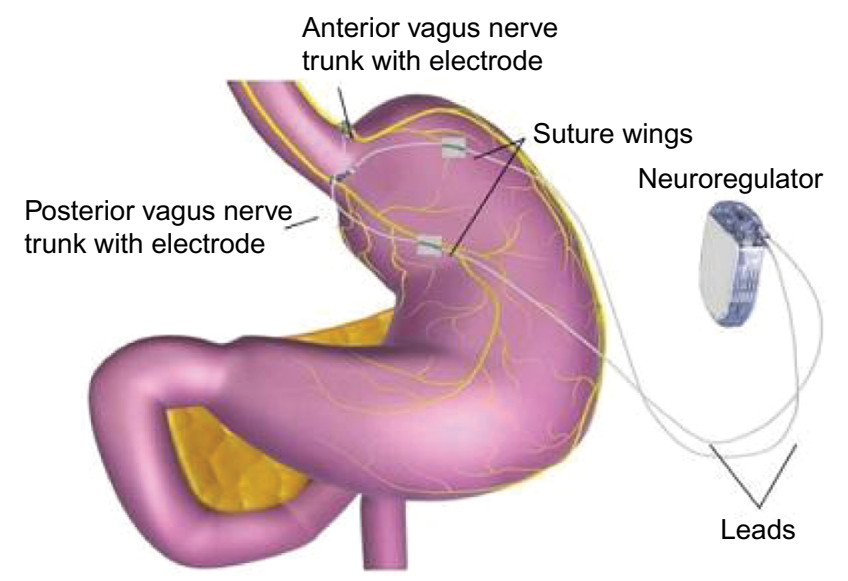

Figure 7 Maestro Rechargeable System (VBLOC device).

Note: Reproduced from www.fda.gov [homepage on the Internet]. Maryland: Food and Drug Administration [updated August 5, 2015]. Available from: http://www.fda. gov/MedicalDevices/ProductsandMedicalProcedures/ObesityDevices/ucm 350I 34. htm. Accessed April I2, 2016. ${ }^{47}$

Abbreviation: VBLOC, vagal blocking for obesity control.

in 2015 (Figure 7). VBLOC is the first weight loss device approved by the FDA since the laparoscopic gastric band in 2001.

Until recently, the vagus nerve has not been widely incorporated as part of the treatment for obesity. One of the earliest reports studying vagotomy for weight loss in animals was printed in 1964, evaluating the effect of vagotomy and pyloroplasty on weight loss in dogs. ${ }^{33} \mathrm{~A}$ small case series first describing the utilization of vagotomy in humans for the treatment of obesity was published in late $1979 .{ }^{34}$ Truncal vagotomy was performed on 13 patients with a mean starting weight of $123 \mathrm{~kg}$, as a treatment for morbid obesity. Weight decreases of 20-30 $\mathrm{kg}$ (range 2-64 kg) were observed during follow-up periods ranging from 4 to 24 months. ${ }^{34}$ Since then, there have been a small number of studies showing reduced calorie consumption and enhanced weight loss results after truncal vagotomy, most likely secondary to reduced liquid calorie intake..$^{35,36}$ However, with the rapid growth of laparoscopic gastric bypass and laparoscopic gastric band in the 1990s and early 2000s and reports of less durable weight loss results with truncal vagotomy (\%EWL less than $25 \%$ and maintenance of weight loss less than 5 years), ${ }^{37}$ the interest in the vagus nerve waned.

The basis for the therapeutic effect of the VBLOC is best understood in the context of the vagus nerve physiology. The vagus nerves are the autonomic link between the brain and the digestive tract. Only $10 \%-20 \%$ of the vagus nerve is composed of efferent fibers that control gastric acid secretion, digestive enzyme secretion, and gastric motility. The remaining $80 \%-90 \%$ of the vagus nerve consists of afferent fibers that send signals regulating satiety and satiation. By sending intermittent high-frequency electrical energy to a cuff around the vagus nerves, there is interruption of vagal nerve signaling which leads to a delay in gastric emptying and therefore early satiety and reduced hunger. ${ }^{38}$ Theoretically, the intermittent nature of therapy is less likely to allow the patient to accommodate to the treatment as is seen with the truncal vagotomy.

The Maestro Rechargeable System consists of two electrodes connected to the anterior and posterior vagus nerves. The electrodes are connected to a rechargeable pulse generator which delivers $5,000 \mathrm{~Hz}$ to each nerve. This leads to complete and reversible nerve block by interrupting the compound action potential. ${ }^{38}$ It has been demonstrated that this blocking therapy significantly downregulates pancreatic exocrine secretion and gastric contractility. ${ }^{39}$ In addition, in a porcine model it was shown that vagus nerve function and histology were not damaged by the intermittent delivery of $5,000 \mathrm{~Hz} \cdot{ }^{35}$ In early human studies, VBLOC therapy led to early fullness and reduced caloric intake without changing dietary composition. ${ }^{40}$ This was a promising finding especially for patients who do not desire the drastic dietary changes that are associated with traditional bariatric surgery.

Implantation of the VBLOC consists of a 60-minute laparoscopic operation with 4-5 small incisions. The anterior and posterior vagus nerves are identified on the intra-abdominal distal esophagus. One electrode is placed on the anterior nerve and another electrode is placed on the posterior nerve. The neuroregulator is then connected to the electrodes and placed in a subcutaneous pocket on the left lower chest wall. After the device is remotely activated, it can be noninvasively modified in two different ways by the health care professional. The number of hours that the device is active can be adjusted and the amplitude delivered to the electrodes can be changed in order to provide optimal therapy. In addition, the device can be deactivated, reactivated, or completely removed without alteration of normal anatomy and physiology.

FDA approval of the Maestro Rechargeable System was achieved after demonstration of safety and efficacy from two major clinical trials, the EMPOWER and the ReCharge trials. ${ }^{41,42}$ The EMPOWER trial was a prospective, randomized, controlled trial, in which the Maestro Rechargeable System was implanted into 294 patients. Patients were between 18 and 65 years old with a BMI between 35 and $45 \mathrm{~kg} / \mathrm{m}^{2}$. These patients were then randomized into the control group, where the device was not activated, or the treatment group, where the device was activated. The activated devices were set to biphasic pulses at a frequency of $5,000 \mathrm{~Hz}$ and an amplitude of 3-8 $\mathrm{mA}$, used to block vagal neural impulses with 5-minute on and off cycles -5 minutes on and 5 minutes off. The control group devices, however, also received impulses, 
albeit much smaller, with intermittent $1,000 \mathrm{~Hz}$ and $3 \mathrm{~mA}$ and continued up to $40 \mathrm{~Hz}$ and $1 \mathrm{~mA}$ during the duration of the "on" cycle. This was to ensure good working order and safety of the device. This study showed that the longer the device was on, the greater was the amount of weight the patients lost. However, the EMPOWER study did not demonstrate any difference in the two groups in \%EWL. ${ }^{41} \mathrm{It}$ was hypothesized that this may have been due to the control group devices being set to also send out electrical impulses, possibly unintentionally blocking the vagal trunks as well. This led to the development of the ReCharge trial. ${ }^{42}$

The ReCharge trial was also a prospective, randomized, controlled trial. ${ }^{42}$ Patients were between 18 and 65 years of age with a BMI between 35 and $45 \mathrm{~kg} / \mathrm{m}^{2}$. A total of 239 patients were randomized in a 2:1 ratio of VBLOC to sham control. The VBLOC device was implanted into the treatment group as described previously in this article. The sham control group patients had the subcutaneous neuroregulator implanted without any connected electrodes. The sham operation consisted of the same number of incisions as the treatment group but without peritoneal penetration. The neuroregulator of the sham group could be programmed similar to the treatment group. All devices were programmed to deliver charges for at least 12 hours a day. Mean \%EWL was measured at 12 months and demonstrated $24.4 \%$ for the VBLOC group and $15.9 \%$ for the sham group (Figure 8 ). Although this was a statistically significant difference $(P=0.002)$, it did not reach the study's goal of showing a superiority margin of $10 \%$ EWL. In regard to safety, VBLOC therapy demonstrated a $3.7 \%$ primary serious adverse event which was well under the $15 \%$ threshold set by the FDA. ${ }^{42}$
Table 2 Comparison of effectiveness between surgical weight loss management and intragastric balloon vs Maestro Rechargeable System

\begin{tabular}{lll}
\hline Study & Procedure & Mean \%EWL at I year \\
\hline Ponce et a $\left.\right|^{31, *}$ & Intragastric balloon & 27.9 \\
Ikramuddin et a $^{42}$ & VBLOC & 24.4 \\
Weichman et al $^{44}$ & LAGB & 37.6 \\
Coleman et al $^{22}$ & LVSG & 56 \\
Higa et al ${ }^{43}$ & LRYGB & 67.8 \\
\hline
\end{tabular}

Notes: *Intragastric balloon: the REDUCE pivotal trial. The control group had a sham endoscopy plus diet and exercise alone, and the active group had the intragastric balloon placed for 24 weeks, then the balloon was removed and these patients also underwent diet and exercise for 24 weeks.

Abbreviations: \%EWL, percent excess weight loss; VBLOC, vagal blocking for obesity control; LAGB, laparoscopic adjustable gastric band; LVSG, laparoscopic vertical sleeve gastrectomy; LRYGB, laparoscopic Roux-en-Y gastric bypass.

The Maestro Rechargeable System is the first weight loss device that has been approved by the FDA for weight loss (2015) since the laparoscopic gastric band in 2001. Initial studies show that although the VBLOC device is not as effective for weight loss as the LVSG or LRYGB, it appears to be a viable option for weight loss in obese patients desiring a "less invasive" procedure for weight loss, or who would not be able to tolerate a more invasive procedure (Table 2). Selection of the correct patient for the VBLOC device depends on patient preference, and surgical and medical risks. Thus, choosing between these therapies will not be an easy task and will require a well thought out plan between the patient and the physician.

The future of this device looks very promising as it appears to affect one of the several feedback gastrointestinal loops that regulate weight. Weight loss is complex with multiple systems trying to prevent weight loss or produce weight regain after it

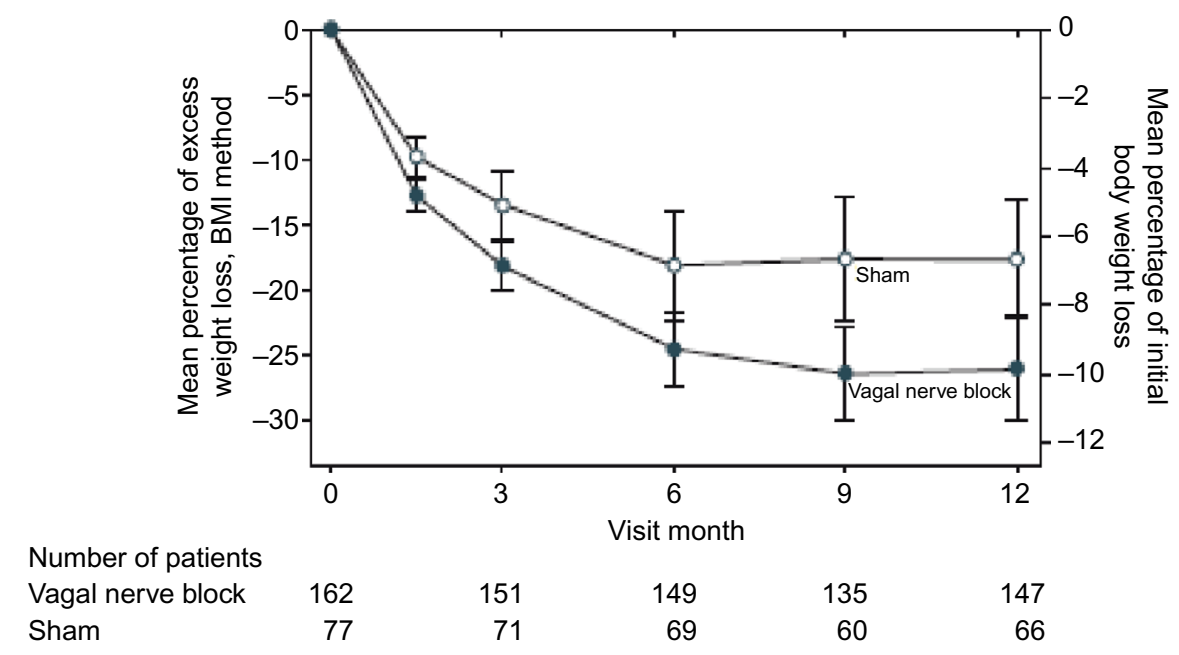

Figure 8 Comparison of weight loss between patients with implanted VBLOC device and patients who underwent a sham procedure.

Notes: Error bars indicate $95 \%$ Cls. Reproduced with permission from JAMA. 2014;12(9):915-922.42 Copyright (C) (2014), by American Medical Association. All rights reserved.

Abbreviations: VBLOC, vagal blocking for obesity control; $\mathrm{Cl}$, confidence interval; BMI, body mass index. 
is lost. ${ }^{45}$ Thus, it is conceivable that in the future this device may be used with other modalities such as medications or even other surgical procedures to enhance its efficacy. Well-designed studies are needed to determine the best usage of this device.

\section{Disclosure}

The authors report no conflicts of interest in this work.

\section{References}

1. Adult Obesity Facts [webpage on the Internet]. Centers for Disease Control and Prevention; 2015 [cited September 21, 2015]. Available from: http://www.cdc.gov/obesity/data/adult.html. Accessed October $15,2015$.

2. Lastra G, Manrique C, Sowers JR. Obesity, cardiometabolic syndrome, and chronic kidney disease: the weight of the evidence. Adv Chronic Kidney Dis. 2006;13(4):365-373.

3. Nunes JP. The risk factor association syndrome as a barisystemic syndrome: a view on obesity and the metabolic syndrome. Med Hypotheses. 2007;68(3):541-545.

4. Isomaa B, Almgren P, Tuomi T, et al. Cardiovascular morbidity and mortality associated with the metabolic syndrome. Diabetes Care. 2001;24(4):683-689.

5. Mingrone G, Panunzi S, De Gaetano A, et al. Bariatric surgery versus conventional medical therapy for type 2 diabetes. N Engl J Med. 2012; 366(17):1577-1585.

6. Schauer P, Kashyap SR, Wolski K, et al. Bariatric surgery versus intensive medical therapy in obese patients with diabetes. NEngl J Med.2012: 366(17):1567-1576.

7. Sjöström L, Narbro K, Sjöström CD, et al. Effects of bariatric surgery on mortality in Swedish obese subjects. N Engl J Med. 2007; 357(8):741-752.

8. Arterburn DE, Olsen MK, Smith VA, et al. Association between bariatric surgery and long-term survival. JAMA. 2015;313(1):62-70.

9. Adams TD, Gress RE, Smith SC, et al. Long-term mortality after gastric bypass surgery. N Engl J Med. 2007;357(8):753-761.

10. ASMBS.org [homepage on the Internet]. Florida: American Society for Metabolic and Bariatric Surgery [published July 2015]. Available from: https://asmbs.org/resources/estimate-of-bariatric-surgery-numbers. Accessed April 8, 2016.

11. Wittgrove AC, Clark GW, Temblay LJ. Laparoscopic gastric bypass, Roux-en-Y: preliminary report of five cases. Obes Surg. 1994;4(4):353-357.

12. Mason EE, Ito C. Gastric bypass. Ann Surg. 1969;170(3):329-339.

13. Kumar R, Lieske JC, Collazo-Clavell ML, et al. Fat malabsorption and increased intestinal oxalate absorption are common after Roux-en-Y gastric bypass surgery. Surgery. 2011;149(5):654-661.

14. Inabnet WB, Quinn T, Gagner M, Urban M, Pomp A. Laparoscopic Roux-en-Y gastric bypass in patients with $\mathrm{BMI}<50$ : a prospective randomized trial comparing short and long limb lengths. Obes Surg. 2005;15(1):51-57.

15. Brolin R. Long limb Roux en Y gastric bypass revisited. Surg Clin N Am. 85:2005:807-817.

16. Marceau P, Hould FS, Simard S, et al. Biliopancreatic diversion with duodenal switch. World J Surg. 1998;22(9):947-954.

17. Mognol P, Chosidow D, Marmuse JP. Laparoscopic sleeve gastrectomy as an initial bariatric operation for high-risk patients: initial results in 10 patients. Obes Surg. 2005;15(7):1030-1033.

18. Consten EC, Gagner M, Pomp A, Inabnet WB. Decreased bleeding after laparoscopic sleeve gastrectomy with or without duodenal switch for morbid obesity using a stapled buttressed absorbable polymer membrane. Obes Surg. 2004;14(10):1360-1366.

19. Esteban Varela J, Nguyen NT. Laparoscopic sleeve gastrectomy leads the U.S. utilization of bariatric surgery at academic medical centers. Surg Obes Relat Dis. 2015;11(5):987-990.
20. Kruger RS, Pricolo VE, Streeter TT, Colacchio DA, Andrade UA. A bariatric surgery center of excellence: operative trends and long-term outcomes. J Am Coll Surg. 2014;218(6):1163-1174.

21. Nguyen NT, Nguyen B, Gebhart A, Hohmann S. Changes in the makeup of bariatric surgery: a national increase in use of laparoscopic sleeve gastrectomy. J Am Coll Surg. 2013;216(2):252-257.

22. Coleman KJ, Huang YC, Hendee F, Watson HL, Casillas RA, Brookey J. Three-year outcomes from a bariatric surgery registry in a large integrated healthcare system. Surg Obes Relat Dis. 2014;10(3):396-404.

23. Peterli R, Borbely Y, Kern B, et al. Early results of the Swiss Multicentre Bypass or Sleeve Study (SM-BOSS): a prospective randomized trial comparing laparoscopic sleeve gastrectomy and Roux-en-Y gastric bypass. Ann Surg. 2013:258(5):690-695.

24. Trastulli S, Desiderio J, Guarino S, et al. Laparoscopic sleeve gastrectomy compared with other bariatric surgical procedures: a systematic review of randomized trials. Surg Obes Relat Dis. 2013;9(5):816-830.

25. Goitein D, Raziel A, Szold A, Sakran N. Assessment of perioperative complications following primary bariatric surgery according to the Clavien-Dindo classification: comparison of sleeve gastrectomy and Roux-Y gastric bypass. Surg Endosc. 2016;30(1):273-278.

26. Dogan K, Gadiot R, Aarts E, et al. Effectiveness and safety of sleeve gastrectomy, gastric bypass, and adjustable gastric banding in morbidly obese patients: a multicenter, retrospective, matched cohort study. Obes Surg. 2015;25(7):1110-1118.

27. Zellmer J, Mathiason M, Kallies K, Kothari S. Is laparoscopic sleeve gastrectomy a lower risk bariatric procedure compared with laparoscopic Roux-en-Y gastric bypass? A meta-analysis. Am J Surg. 2014; 208(6):903-910.

28. Young M, Gebhart A, Phelan M, Nguyen N. Use and outcomes of laparoscopic sleeve gastrectomy vs laparoscopic gastric bypass: analysis of the American College of Surgeons NSQIP. J Am Coll Surg. 2015;220(5):880-885.

29. Toolabi K, Golzarand M, Farid R. Laparoscopic adjustable gastric banding: efficacy and consequences over a 13-year period. Am J Surg. Epub 2015 July 31.

30. Aarts EO, Dogan K, Koehestanie P, Aufenacker TJ, Janssen IMC, Berends FJ. Long-term results after laparoscopic adjustable gastric banding: a mean fourteen year follow-up study. Surg Obes Relat Dis. 2014;10(4):633-640.

31. Ponce J, Woodman G, Swain J, et al. The REDUCE pivotal trial: a prospective, randomized controlled pivotal trial of a dual intragastric balloon for the treatment of obesity. Surg Obes Relat Dis. 2015;11(4):874-881.

32. Waataja JJ, Tweden KS, Honda CN. Effects of high-frequency alternating current on axonal conduction through the vagus nerve. J Neural Eng. 2011;8(5):056013.

33. Frederick PL, Craig TV. The effect of vagotomy and pyloroplasty on weight loss and survival of dogs after massive intestinal resection. Surgery. 1964;56:135-143.

34. Kral JG. Vagotomy as a treatment for morbid obesity. Surg Clin North Am. 1979;59(6):1131-1138.

35. Gortz L, Bjorkman AC, Andersson H, Kral JG. Truncal vagotomy reduces food and liquid intake in man. Physiol Behav. 1990;48(6):779-781.

36. Kral JG, Gortz L, Hermansson G, Wallin GS. Gastroplasty for obesity: long-term weight loss improved by vagotomy. World J Surg. 1993; 17(1):75-78.

37. Fobi MA. Operations that are questionable for control of obesity. Obes Surg. 1993;3(2):197-200.

38. Berthoud HR. Vagal and hormonal gut-brain communication: from satiation to satisfaction. Neurogastroenterol Motil. 2008;20(Suppl 1):64-72.

39. Tweden KS, Sarr MG, Camilleri M, Kendrick ML, Moody FG, Bierk MD. Vagal blocking for obesity control (VBLOC): studies of pancreatic and gastric function and safety in a porcine model. Surg Obes Relat Dis.2005;2:301-302.

40. Herrera MF, Burton DD, Pantoja JP, et al. Intermittent vagal blocking with an implantable device reduces maximum tolerated volume during a standardized nutrient drink test in obese subjects. Obes Surg. 2009; 19(8);1012 
41. Sarr M, Billington CJ, Brancatisano R, et al. The EMPOWER study: randomized, prospective, double-blind multicenter trial of vagal blockade to induce weight loss in morbid obesity. Obes Surg.2012;22(11):1771-1782.

42. Ikramuddin S, Blackstone RP, Brancatisano A, et al. Effect of reversible intermittent intra-abdominal vagal nerve blockade on morbid obesity the recharge randomized clinical trial. JAMA. 2014;312(9):915-922.

43. Higa K, Ho T, Tercero F, Yunus T, Boone KB. Laparoscopic Roux-en-Y gastric bypass: 10-year follow-up. Surg Obes Relat Dis. 2011;7(4):516-525.

44. Weichman K, Ren C, Kurian M, et al. The effectiveness of adjustable gastric banding: a retrospective 6-year U.S. follow-up study. Surg Endosc. 2011;25(2):397-403.

45. Fujioka, K. Current and emerging medications for overweight or obesity in people with comorbidities. Diabetes Obes Metab. 2015;17(11): 1021-1032.

46. The Cleveland Clinic. Weight Loss Surgery for Severely Obese Patients: Information for Physicians from the Cleveland Clinic Bariatric and Metabolic Institute. Cleveland: The Cleveland Clinic Foundation; 2008.

47. www.fda.gov [homepage on the Internet]. Maryland: Food and Drug Administration [updated August 5, 2015]. Available from: http://www fda.gov/MedicalDevices/ProductsandMedicalProcedures/ObesityDevices/ucm350134.htm. Accessed April 12, 2016.
48. Himpens J, Dapri G, Cadiere GB. A prospective randomized study between laparoscopic gastric banding and laparoscopic isolated sleeve gastrectomy: results after 1 and 3 years. Obes Surg. 2006;16: 1450-1456.

49. Kehagias I, Karamanakos SN, Argentou M, Kalfarentzos F. Randomized clinical trial of laparoscopic Roux-en-Y gastric bypass versus laparoscopic sleeve gastrectomy for the management of patients with BMI $<50$ kg/m2. Obes Surg. 2011;21:1650-1656.

50. Lakdawala MA, Muda NH, Goel S, Bhasker A. Single-incision sleeve gastrectomy versus conventional laparoscopic sleeve gastrectomy--a randomised pilot study. Obes Surg. 2011;21:1774-1770.

51. Langer FB, Reza Hoda MA, Bohdajalian A, et al. Sleeve gastrectomy and gastric banding: effects on plasma ghrelin levels. Obes Surg. 2005;15:1024-1029

52. Lee WJ, Chong K, Ser KH, et al. Gastric bypass vs sleeve gastrectomy for type 2 diabetes mellitus: a randomized controlled trial. Arch Surg. 2011;146:143-148.

53. Peterli R, Steinert RE, Woelnerhanssen B, et al. Metabolic and hormonal changes after laparoscopic Roux-en-Y gastric bypass and sleeve gastrectomy: a randomized, prospective trial. Obes Surg. 2012;16: 1116-1122.
Medical Devices: Evidence and Research

\section{Publish your work in this journal}

Medical Devices: Evidence and Research is an international, peerreviewed, open access journal that focuses on the evidence, technology, research, and expert opinion supporting the use and application of medical devices in the diagnosis, monitoring, treatment and management of clinical conditions and physiological processes. The identification of novel

\section{Dovepress}

devices and optimal use of existing devices which will lead to improved clinical outcomes and more effective patient management and safety is a key feature. The manuscript management system is completely online and includes a quick and fair peer-review system. Visit http://www. dovepress.com/testimonials.php to read real quotes from authors. 